\title{
Scimitar syndrome
}

INSERM

\section{Source}

INSERM. (1999). Orphanet: an online rare disease and orphan drug data base. Scimitar syndrome. ORPHA:185

Scimitar syndrome is characterized by a combination of cardiopulmonary anomalies including partial anomalous pulmonary venous return connection of the right lung to the inferior caval vein leading to the creation of a left-to-right shunt. 